\title{
Stochastic Modeling of Solidification Structure in Alloy 718 Remelt Ingots
}

\author{
Laurentiu Nastac, Suresh Sundarraj, and Kuang-O Yu \\ Concurrent Technologies Corporation, \\ 1450 Scalp Avenue, Johnstown, PA 15904
}

\begin{abstract}
A general numerical approach was developed to model the formation of grain structure and secondary phases ( $\mathrm{NbC}$ and eutectic-Laves phases) during the solidification of secondary remelt ingots. The model was applied to simulate the grain structure formation during solidification of VAR (Vacuum Arc Remelting) and ESR (Electroslag Remelting) alloy 718 ingots. Results from the model such as pool profile, grain-growth pattern, grain size, secondary dendrite arm spacing, amount of eutectic $\gamma$-Laves phase, and amount of carbides compared very well with previously published data for alloy 718 .

\section{Introduction}

Quality is one of the major concerns in the manufacture of high-performance superalloy components (turbine and compressor discs) for aerospace and other commercial applications. The materials for these components are made by secondary remelting processes such as VAR (Vacuum Arc Remelting) and ESR (Electroslag Remelting) which involve a continuous casting operation to produce an ingot. The quality of the cast ingots produced by these processes is governed by two factors: (1) grain structure formation (columnar and equiaxed morphologies, as well as the columnar-to-equiaxed transition (CET)) and (2) micro/macrosegregation phenomena (formation of freckles, as well as of Laves phases and carbides). Process modeling has become a viable tool to optimize the ESR and VAR processes. A comprehensive modeling approach to simulate ingot solidification phenomena in secondary remelting processes is depicted in Figure 1. Based on process and material parameter input data, the deterministic model performs macroscopic mass, heat transfer, fluid flow, electromagnetic, and species transport computations to provide temperature, velocity, and concentration fields as outputs. From the macroscopic temperature field, the pool profile and pool size, as well as the shape and size of the mushy region, can be determined. In addition, from the concentration field, macrosegregation related defects, such as freckles and tree-ring patterns, can be obtained. A stochastic model uses the results from the macro-model to predict grain structure evolution of solidifying ingots. It also computes the grain size and CET, as well as microsegregation-related defects such as the amount and size of secondary phases (Laves phases and $\mathrm{NbC}$ in alloy 718). The relevance of the stochastic model is that the simulated structures can be directly compared with actual structures obtained from experiments. The computer model becomes a "dynamic metallographic microscope."

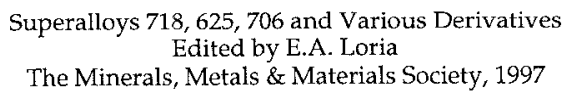




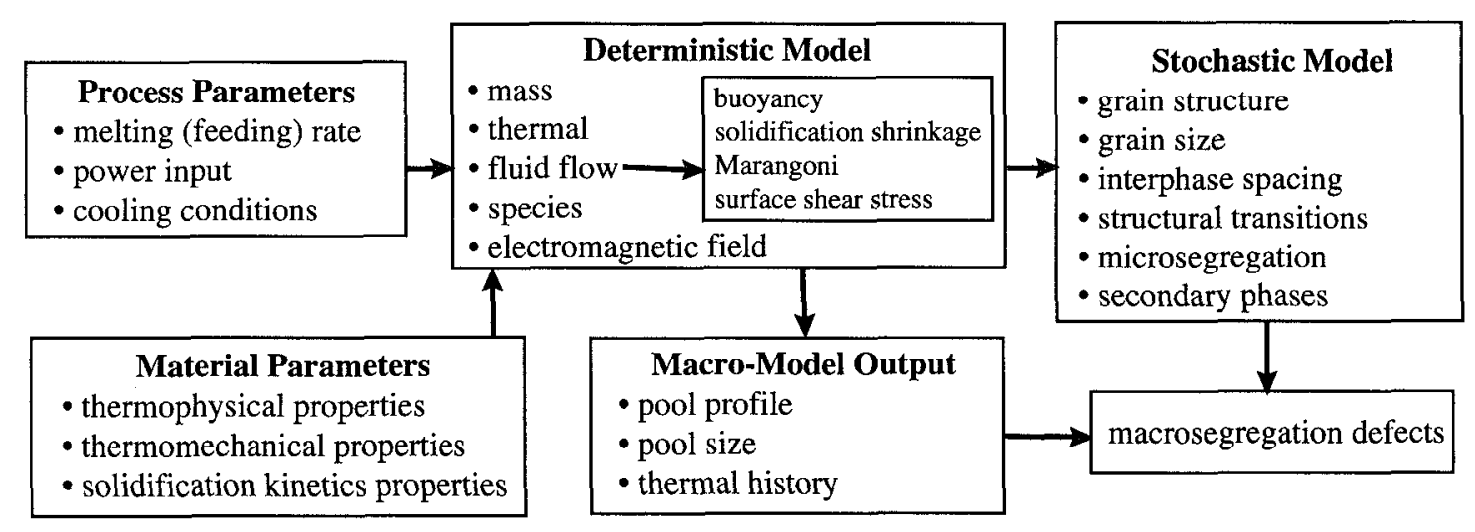

Figure 1 - Flow diagram showing modeling requirements for secondary remelting processes.

The stochastic model is comprehensive because the competition between nucleation and grain growth kinetics of various phases is considered. Furthermore, grain impingement is directly accounted for in the model.

This paper investigates the effects of macroscopic transport of mass and energy on the pool profile and on the formation of grain structure and secondary phases during the solidification of VAR and ESR alloy 718 ingots. In this regard, efforts were directed at developing a comprehensive model that follows the approach shown in Figure 1. The model consists of three components: (1) a deterministic macroscopic approach to model the mass and heat transfer during the ingot solidification process, (2) a stochastic microscopic approach to simulate the evolution of grain structure, and (3) a stochastic microscopic approach to simulate the evolution of secondary phases.

\section{Model Description}

\section{A Deterministic Macro-Model for the Calculation of Mass and Energy Transport}

A moving grid, fully implicit, control-volume method was developed to describe the transient macro-transport phenomena in solidifying continuously cast ingots. The model was implemented in COMPACT ${ }^{\mathrm{TM}}$ [1]. A detailed description of this macro-model is described in Ref. [2]. For an axisymmetric geometry, the appropriate heat-transfer boundary conditions (BCs) for these processes are: symmetry at the ingot center, convection and radiation at the ingot edge and ingot bottom, and process specific BCs at the ingot top to account for the heat input (due to metal flow into the domain) and heat loss (due to radiation from the top surface).

\section{A Stochastic Micro-Model for Modeling the Formation of Structure in Castings}

The present stochastic approach differs from the classical "Cellular Automata" technique [3] in that it uses thermal history results from the deterministic model described in the previous paragraph [4]. The development of the stochastic model for grain structure evolution is described in detail in Ref. [2]. This description includes nucleation and growth kinetics, as well as the growth anisotropy and grain selection mechanisms. The required input data to perform stochastic calculations are: (1) the local cooling rates calculated at the liquidus and solidus temperatures, (2) the local time-dependent temperature gradients in the mushy zone also calculated at the liquidus and solidus temperatures, and (3) the local solidification start and end times. These data are provided by a macroscopic model for each computational cell. Local cooling rates calculated at the liquidus temperature are used to compute the nucleation parameters. Local average cooling rates and time-dependent temperature gradients in the mushy zone are used to compute the grain growth parameters. 
During solidification of remelt ingots, at least three grain morphologies are encountered: equiaxed grains, columnar grains solidified under a variable $\mathrm{G} / \mathrm{V}$ ratio, and columnar grains solidified under a relatively constant $G / V$ ratio, where $G$ and $V$ are the local temperature gradient and solid-liquid (S/L) interface velocity of the mushy region, respectively. All aforementioned morphologies, as well as the columnar-to-equiaxed transition are driven more or less by the same solidification mechanism, i.e., the nucleation and growth competition of various phases in the mushy region. The stochastic models for equiaxed and columnar grains solidified under a variable G/V ratio are described in Refs. [3, 5]. The columnar structure solidified under a relatively constant $G / V$ ratio, which is perhaps the most common morphology encountered during secondary remelting processes, is presented in Ref. [2].

A RAM memory size of 50 bytes/ $\mu \mathrm{VE}$ or $20 \mathrm{Kbytes} / \mathrm{VE}$ (one macro-volume element (VE) of $5 \mathrm{~mm}$ spacing with $20 \times 20 \mu \mathrm{VEs}$ ) is needed in the present stochastic calculations. To simulate the structure of an ingot with a height $(\mathrm{H})$ of $1.0 \mathrm{~m}$ and radius $(\mathrm{R})$ of $0.25 \mathrm{~m}$, a grid resolution of $4000 \times 1000$ ( 4 million $\mu$ VEs of $250 \mu \mathrm{m}$ spacing each) is used. For this grid size, the CPU-time and the RAM memory required to obtain the simulated ingot structure are on the order of $4 \mathrm{CPU}$ hours on an SGI-200 MHz Challenger workstation and 200 Mbytes, respectively. In the present approach, during a time-step calculation, both first- and secondorder nearest neighbors are scanned for any active $\mu \mathrm{VE}$. When a given $\mu \mathrm{VE}$ and its neighbors become solid, the scanning procedure stops for that particular $\mu \mathrm{VE}$. When this scanning procedure is used, computer memory and CPU-time are decreased by at least one half of those required for standard (without the scanning procedure) stochastic calculations.

$\underline{\text { A Stochastic Model for Modeling Secondary Phases During Solidification of Alloy } 718 \text { Ingots }}$

The importance of modeling the formation of NbC/Laves phases in alloy 718 has been discussed broadly in literature (see the list of references in $[8,9,10]$ ). It is also known that the distribution and amount of carbides and Laves phases in alloy 718 are affected by the solidification path. The volume fraction of solid is a function of local growth velocity, solidification time, solidus temperature, and local temperature gradient. The redistribution of elements strongly affects the phase cvolution in common superalloys with respect to temperature, as well as their mechanical properties and surface stability at elevated temperatures.

The primary goal of this work was to develop a solidification kinetics model to predict the evolution of $\mathrm{NbC}$ and Laves phases during ingot solidification. Previous studies on alloy 718 showed that both $\mathrm{NbC}$ and Laves phases produce intergranular liquid films due to the intergranular distribution of $\mathrm{Nb}$ and $\mathrm{C}[9,10]$. Also, the ability of Laves phase to promote intergranular liquation cracking (microfissuring and hot cracking) during heat treatment is much higher than that of $\mathrm{NbC}$. This is because the temperature for the formation of Laves phases is usually lower than that for $\mathrm{NbC}$ (i.e., liquation initiates at the eutectic-Laves temperature). In Refs. [9, 10], it was demonstrated that the carbon content of alloy 718 directly affects the volume fraction of carbides. Note, that the as-cast alloy could contain a higher volume fraction of $\mathrm{NbC}$ and Laves phases than what the phase diagram suggests due to the microsegregation during solidification. The relative volume fractions of both $\mathrm{NbC}$ and Laves phases depend on the $\mathrm{C} / \mathrm{Nb}$ ratio. Alloys with high $\mathrm{C} / \mathrm{Nb}$ ratio will have a higher volume fraction of carbides than alloys with low $\mathrm{C} / \mathrm{Nb}$ ratio.

In developing a solidification kinetics model for predicting the formation of $\mathrm{NbC/Laves}$ phases in alloy 718, the following assumptions were made: instantaneous nucleation, carbide growth in the liquid, no interference between growing carbides, carbides are either pushed or engulfed by the $S / L$ interface, volume diffusion-limited growth of carbides, and binary diffusion couple. The model accounts for: (1) nucleation and growth of columnar or 
equiaxed dendritic grains, (2) growth/remelting of spherical instabilities, (3) nucleation and growth of $\mathrm{NbC}$ assuming that the slow step is the volume diffusion of carbon from the liquid to the $\mathrm{NbC}$ /liquid interface, (4) redistribution of $\mathrm{Nb}$ and $\mathrm{C}$ concentrations, (5) redistribution of $\mathrm{NbC}$ particles between the solid and liquid phases at the spherical instability level, and (6) nucleation and growth of Laves phases. These features are further discussed below.

(1) The dendritic growth (columnar or equiaxed) is based on the alloy 718 pseudo-binary phase diagram [3], where the primary driving force for growth is the $\mathrm{Nb}$ diffusion in the liquid. The models for equiaxed and columnar dendritic growth of alloy 718 are described elsewhere $[2,3,11]$. These are applied to calculate the evolution of the primary $(\gamma)$ phase.

(2) A coarsening (thickening) model for spherical instabilities was developed in Refs. [3, 11]. It is assumed that the coarsening mechanism is analogous to Oswald ripening of precipitates. The model considers the dynamic nature of the spherical coarsening process through the evolution of the fraction of solid and time-variation of liquid concentration in the mush. The mechanism of coalescence of instabilities is ignored in this model. The final result is $[3,11]$ :

$$
V_{S}=\frac{0.75}{\left(R_{t}^{*}\right)^{2}} \frac{A}{\left\langle C_{L}\right\rangle^{L}} \frac{f_{S}^{1 / 3}}{1-f_{S}^{1 / 3}} \quad \text { with } \quad f_{S}=\left(\frac{R_{t}^{*}}{R_{f}}\right)^{3} \quad \text { and } \quad R_{t_{0}}^{*}=\frac{\Gamma}{\sigma^{*} \Delta T}
$$

Here, $f_{s}$ is the fraction of solid, $V_{s}$ is the $S / L$ interface velocity of spherical instabilities, $R_{f}$ is one half of the average spacing between instabilities (at time $t$ ), $R_{t}^{*}$ is the instability radius at time $t, R_{t_{0}}^{*}$ is the initial instability radius at time $t_{o}, \sigma^{*}$ is a stability constant of the order of $1 /\left(4 \pi^{2}\right),\left\langle C_{L}\right\rangle^{L}$ is the intrinsic volume avcrage liquid concentration, $\Delta \mathrm{T}$ is the undercooling, and $A=\frac{D_{L} \Gamma}{m_{L}(k-1)}$, where $D_{L}$ is the liquid diffusivity, $\Gamma$ is the Gibbs-Thomson coefficient, $\mathrm{m}_{\mathrm{L}}$ is the liquidus slope, and $\mathrm{k}$ is the partition ratio.

(3) The growth mechanism of $\mathrm{NbC}$ is governed by the carbon diffusion from the liquid to the $\mathrm{NbC} / \mathrm{L}$ interface and by the reaction kinetics between $\mathrm{Nb}$ and $\mathrm{C}$ [8]. Accordingly, $\mathrm{C}$ is depleted at the $\mathrm{NbC} / \mathrm{L}$ interface, and the amount of $\mathrm{NbC}$ precipitated depends on the volume diffusion of $\mathrm{C}$ from the liquid to the $\mathrm{NbC/L}$ interface. It is also assumed that the carbides instantaneously nucleate at the equilibrium solidification temperature of alloy 718 . The solution of the spherical volume diffusion-limited growth is described by an averaging method provided in Ref. [8]:

$$
\mathrm{V}_{\mathrm{NbC}}=\frac{1}{\phi_{\mathrm{NbC}}}\left(\frac{\mathrm{D}_{\mathrm{C}}^{\mathrm{L}}}{\mathrm{R}_{\mathrm{D}}-\mathrm{R}_{\mathrm{NbC}}^{*}}\right) \frac{\left\langle\mathrm{C}_{\mathrm{L}}\right\rangle_{\mathrm{C}}^{\mathrm{L}}}{\mathrm{C}_{\mathrm{NbC}}} \quad \text { with } \quad \mathrm{R}_{\mathrm{D}}=\frac{3}{4 \pi}\left[\frac{\mathrm{V}_{\mathrm{L}}}{\overline{\mathrm{N}}_{\mathrm{NbC}}^{\mathrm{L}}}\right]^{1 / 3}
$$

Here, $\mathrm{V}_{\mathrm{NbC}}$ is the growth velocity of the $\mathrm{NbC}$ plaase, $\mathrm{D}_{\mathrm{C}}^{\mathrm{L}}$ is the liquid carbon diffusivity, $\left\langle C_{L}\right\rangle_{C}^{L}$ is the intrinsic average liquid carbon concentration, $C_{N b c}$ is the carbon concentration in $\mathrm{NbC}, \mathrm{R}_{\mathrm{NbC}}^{*}$ is the actual growing carbide radius, $\mathrm{v}_{\mathrm{L}}$ is the volume of liquid between instabilities, $\overline{\mathrm{N}}_{\mathrm{NbC}}^{\mathrm{L}}$ is the average number of $\mathrm{NbC}$ particles in $\mathrm{v}_{\mathrm{L}}$, and $\phi_{\mathrm{NbC}}$ is the shape factor of spherical $\mathrm{NbC}$ that considers the real geometry of the $\mathrm{NbC}$ (blocky type). In this work the shape factor of the $\mathrm{NbC}$ is considered to have an average value of 0.64 [8].

(4) The redistribution of both $\mathrm{C}$ and $\mathrm{Nb}$ is calculated with the modified model described in Ref. [12]. The main assumptions are: solute transport is calculated in both solid and liquid phases assuming Fick's law for binary systems in spherical coordinates, planar S/L interface in 
local equilibrium, closed system, and constant initial liquid concentration. The overall mass balance is used to couple the concentration fields in both the solid and liquid phases. The solution of this diffusion couple is a modified version of the Nastac and Stefanescu model [12]. It includes a sink term ( $\mathrm{Q}$ in Eq. (3)) to account for the $\mathrm{C}$ and $\mathrm{Nb}$ depletion because of $\mathrm{NbC}$ phase growth. Thus, the interface concentration, $\mathrm{C}_{\mathrm{L}}^{*}$, of both $\mathrm{C}$ and $\mathrm{Nb}$ is described by:

$$
C_{L}^{*}=\frac{C_{o}\left(k I_{S}+I_{L}-\frac{1}{3}\right)+Q}{k I_{S}+I_{L}-\frac{1}{3}+\frac{(1-k) f_{S}}{3}} \quad \text { with } \quad Q=\bar{N}_{N b C}^{L} \frac{v_{N b C}^{*}}{v_{\gamma}} \frac{\rho_{\mathrm{NbC}}}{\rho_{\gamma}} C_{N b C}
$$

Here, $I_{L}$ and $I_{S}$ are described by Eq. (31) in Ref. [11], $C_{o}$ is the initial concentration of the alloy, $\mathrm{k}$ is the partition coefficient, $\mathrm{v}_{\mathrm{NbC}}^{*}$ is the actual carbide volume, $\mathrm{v}_{\gamma}$ is the volume of the element over which the mass balance is calculated, $\rho_{\mathrm{NbC}}$ is the carbide density, $\rho_{\gamma}$ is the alloy 718 density, $\mathrm{C}_{\mathrm{NbC}}$ is either $\mathrm{C}$ or $\mathrm{Nb}$ concentration in $\mathrm{NbC}$, and $\overline{\mathrm{N}}_{\mathrm{NbC}}^{\mathrm{L}}$ is the average number of $\mathrm{NbC}$ particles in the liquid. The intrinsic average concentration in the liquid phase, required in Eqs. (1) and (2), is calculated with Eq. (32) in Ref. [11].

(5) It has been generally accepted that there is a critical velocity for pushing/engulfment transition (PET) of dispersed second-phase particles by an advancing S/L interface [13, 14]. Non-wetting $\mathrm{NbC}$ particles are either pushed or engulfed by the $\mathrm{S} / \mathrm{L}$ interface. In general, engulfment will lead to more uniform distribution of $\mathrm{NbC}$ particles, while pushing will result in segregation of $\mathrm{NbC}$ particles. Redistribution of $\mathrm{NbC}$ particles between the solid and liquid phases significantly affects not only the size and amount of NbC particles, but also the amount of Laves phases. Therefore, it is important to model particle redistribution during solidification of alloy 718 . Unfortunately, there is no mathematical model that can completely describe this phenomenon. A comprehensive stochastic model that can describe the redistribution of $\mathrm{NbC}$ particles during the solidification of alloy 718 was developed and is outlined below.

Similar to Scheil's model for an open system [15], this present model assumes that there is no movement of particles in the solid, and that particles are uniformly distributed in the liquid. Accordingly, the following overall mass balance can be written:

$$
\bar{N}_{N b C}=\bar{N}_{N b C}^{L}\left(1-f_{S}\right)+\int_{0}^{f_{S}} N_{N b C}^{S} d f \quad \text { with } \quad \bar{N}_{N b C}=\frac{C_{\gamma}}{C_{N b C}} \frac{\rho_{N b}}{\rho_{N b C}} \frac{v_{f}}{v_{N b C}^{f}}
$$

Here, $\overline{\mathbf{N}}_{\mathrm{NbC}}$ is the average number of $\mathrm{NbC}$ particles in the volume element, $\mathrm{N}_{\mathrm{NbC}}^{\mathrm{S}}$ is the number of $\mathrm{NbC}$ particles in the solid in the proximity of the $\mathrm{S} / \mathrm{L}$ interface, $\rho_{\mathrm{NbC}}$ and $\mathrm{v}_{\mathrm{NbC}}^{\mathrm{f}}$ are the density and final volume of the $\mathrm{NbC}$ phase, respectively, and $\mathrm{C}_{\mathrm{NbC}}$ is the $\mathrm{C}$ concentration in the $\mathrm{NbC}$ phase.

Following Hunt's concept [14], an effective partition coefficient is introduced as:

$$
\mathrm{k}_{\mathrm{E}}=\frac{\mathrm{N}_{\mathrm{NbC}}^{\mathrm{S}}}{\overline{\mathrm{N}}_{\mathrm{NbC}}^{\mathrm{L}}}=\left(1+\frac{\mathrm{V}_{\mathrm{P}}}{\mathrm{V}_{\mathrm{S}}}\right) \mathrm{F}_{\mathrm{PE}}
$$

Here, $F_{\mathrm{PE}}$ is a parameter that describes PET ( 0 for pushing and 1 for engulfment), $V_{\mathrm{P}}$ is the particle velocity, and $V_{S}$ is the $S / L$ interface velocity as described by Eq. (1). The particle velocity is dictated by the fluid flow around the particle. For a horizontal flow, the particle velocity $\left(\mathrm{V}_{\mathrm{p}}\right)$ is [14]: 


$$
\mathrm{V}_{\mathrm{P}}=\frac{2 \mathrm{R}_{\mathrm{NbC}}^{*^{2}}\left(\rho_{\mathrm{NbC}}-\rho_{\gamma}\right) \mathrm{g}}{9 \mu \beta}
$$

Here, $\mathrm{g}$ is the acceleration due to gravity, $\mu$ is the liquid viscosity, $\beta=1$ for a particle in an unbounded liquid (Stokes's law), $\mathrm{R}_{\mathrm{NbC}}^{*}$ is the actual $\mathrm{NbC}$ radius, and $\beta=\frac{\mathrm{R}_{\mathrm{NbC}}^{*}}{\mathrm{~d}}$ for a particle approaching the $S / L$ interface, where $d$ is the particle/interface separation distance behind the particle. $F_{P E}$ is a function of the critical velocity of PET. If rand $\leq \mathrm{P}_{\mathrm{PE}}$ then $\mathrm{F}_{\mathrm{PE}}=1$, otherwise, $F_{\mathrm{PE}}=0$, where rand is a computer-generated random number which takes values between zero and one. The probability of PET is:

$$
\mathrm{P}_{\mathrm{PE}}=\frac{\mathrm{V}_{\mathrm{S}}}{\mathrm{V}_{\mathrm{PE}}} \quad \text { with } \quad \mathrm{V}_{\mathrm{PE}}=\frac{\mathrm{a}_{0} \Delta \sigma_{\mathrm{o}}}{12 \mu \mathrm{R}_{\mathrm{NbC}}^{*}} \frac{\mathrm{K}_{\gamma}}{\mathrm{K}_{\mathrm{NbC}}}
$$

Here, $V_{\mathrm{PE}}$ is the critical velocity of PET derived at [13] for a flat interface and a pure metal, $\Delta \sigma_{0}$ is the interfacial energy difference, $a_{0}$ is the atomic distance, and $K_{\gamma}$ and $K_{N b c}$ are the thermal conductivities of the alloy 718 and $\mathrm{NbC}$ particles, respectively.

(6) The Laves phase starts to form when the concentration of $\mathrm{Nb}$ reaches the eutectic $(\gamma+$ Laves) composition which is $19.1 \mathrm{wt}$. \% Nb. The kinetics of Laves is very high due to its morphology (eutectic or globular type-divorced eutectic) and appearance as discontinuous thin films at grain boundaries. It is assumed that the amount of the Laves phase is directly related to $\mathrm{Nb}$ concentration $[3,8,11]$.

\section{$\underline{\text { Results and Discussion }}$}

\section{Modeling Parameters}

A detailed description of the ESR and VAR processes is discussed in Refs. [2, 7, 16-18]. The boundary conditions, ingot dimensions, nucleation and growth kinetics data of alloy 718 , control parameters of the VAR and ESR processes, and thermophysical properties of alloy 718 are outlined in Table 1, Ref. [2]. The casting speed was calculated with $\mathrm{V}_{\text {cast }}=4 \dot{\mathrm{m}}_{\text {pour }} / \rho \pi \mathrm{D}^{2}$, where $\dot{\mathrm{m}}_{\text {pour }}$ is the casting rate and $\mathrm{D}$ is the ingot diamctcr. Data used in micro-modeling of alloy 718 are presented in Table I. Data required to calculate the critical velocity of PET are: $g=9.81 \mathrm{~m} \mathrm{~s}^{-2}, \mu=0.005 \mathrm{~Pa} \mathrm{~s}, \mathrm{a}_{0}=2 \times 10^{-10} \mathrm{~m}$, and $\Delta \sigma_{0}=1 \mathrm{~N} \mathrm{~m}^{-1}$ [13]. The measured final NbC particle radius, $\mathrm{R}_{\mathrm{NbC}}^{\mathrm{f}}$, versus cooling rate is expressed as [8]: $\mathrm{R}_{\mathrm{NbC}}^{\mathrm{f}}=4 \times 10^{-6}-2 \times 10^{-7} \dot{\mathrm{T}}$, where $\dot{\mathrm{T}}$ is the cooling rate in $\mathrm{K} \mathrm{s}^{-1}$ and $\mathrm{R}_{\mathrm{NbC}}^{\mathrm{f}}$ is in $\mu \mathrm{m}$.

Table I Data used in micro-modeling of alloy $718[2,3,8,11]$

\begin{tabular}{|c|c|c|c|c|c|}
\hline Element & $\mathrm{D}_{\mathrm{S}}\left[\mathrm{m}^{2} \mathrm{~s}^{-1}\right]$ & $\mathrm{D}_{\mathrm{L}}\left[\mathrm{m}^{2} \mathrm{~s}^{-1}\right]$ & $\rho\left[\mathrm{kg} \mathrm{m}^{-3}\right]$ & $\mathrm{k}$ & $\mathrm{C}_{\text {eut }}$ [wt. \%] \\
\hline $\mathrm{Nb}$ & $56 \times 10^{-5} \exp \left(-2.8 \times 10^{5} / \mathrm{RT}\right)$ & $1 \times 10^{-9}$ & 8400 & 0.48 & 19.1 \\
\hline $\mathrm{C}$ & $2 \times 10^{-10}$ & $2 \times 10^{-9}$ & 2400 & 0.2 & 2.22 \\
\hline
\end{tabular}

\begin{tabular}{|c|c|c|c|c|c|c|c|c|}
\hline Phase & $\begin{array}{c}\mathrm{L} \\
{\left[\mathrm{J} \mathrm{kg}^{-1}\right]}\end{array}$ & $\begin{array}{c}\Gamma \\
{[\mathrm{K} \mathrm{m}]}\end{array}$ & $\begin{array}{c}\rho \\
{\left[\mathrm{kg} \mathrm{m}^{-3}\right]}\end{array}$ & $\begin{array}{c}\mathrm{K} \\
{\left[\mathrm{W} \mathrm{m}^{-1} \mathrm{~K}^{-1}\right]}\end{array}$ & $\begin{array}{c}\mathrm{m}_{\mathrm{L}} \\
{\left[\mathrm{K} \mathrm{wl.} \mathrm{\%}^{-1}\right]}\end{array}$ & $\begin{array}{c}\mathrm{T}_{\mathrm{L}} \\
{\left[{ }^{\circ} \mathrm{C}\right]}\end{array}$ & $\begin{array}{c}\mathrm{C} \\
{[\text { wt. \%] }}\end{array}$ & $\begin{array}{c}\mathrm{Nb} \\
{[\text { wt. \%] }}\end{array}$ \\
\hline $\mathrm{NbC}$ & 435000 & - & 7200 & 85.0 & - & 1330 & 11.0 & 89.0 \\
\hline Alloy 718 & 295000 & $3 \times 10^{-7}$ & 7620 & 30.0 & -10.83 & 1330 & 0.06 & 5.25 \\
\hline
\end{tabular}




\section{Grain Structure Simulation of VAR and ESR Alloy 718 Ingots}

Grain growth direction and micro/macrosegregation-related defects, such as freckles and tree-ring patterns in alloy 718 , are directly related to the size and profile of the melting pool. The pool characteristics are mostly controlled by the casting rate and energy input. They are also strongly dependent on the ingot diameter. Grain size and shape, as well as micro/macrosegregation patterns are strongly influenced by the heat-extraction rate at the metal/mold interface. Figure 2 shows simulated structures of alloy 718 remelt ingots made by the VAR and ESR processes. In these pictures, the black color represents the mushy zone, the light gray describes the liquid region (melting pool), and the remaining area shows the solidified grain structure.

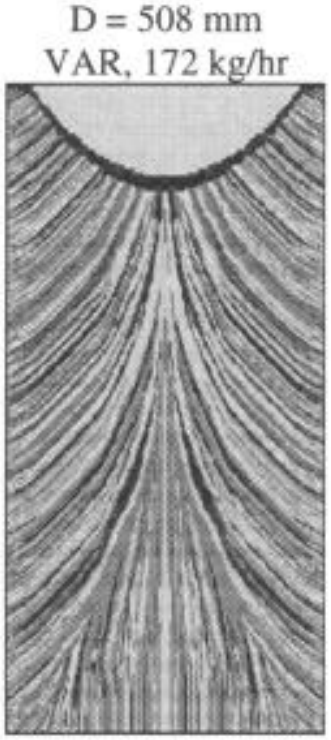

a)

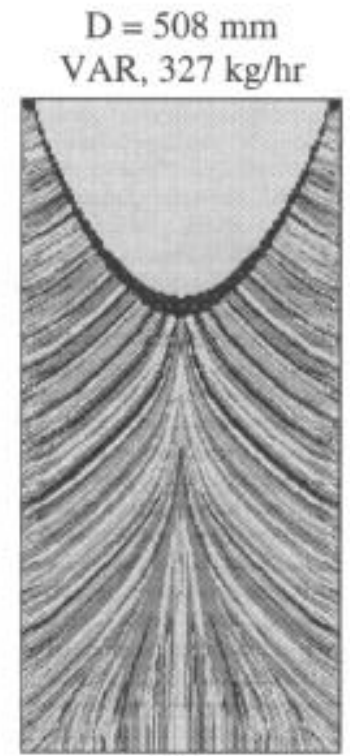

b)

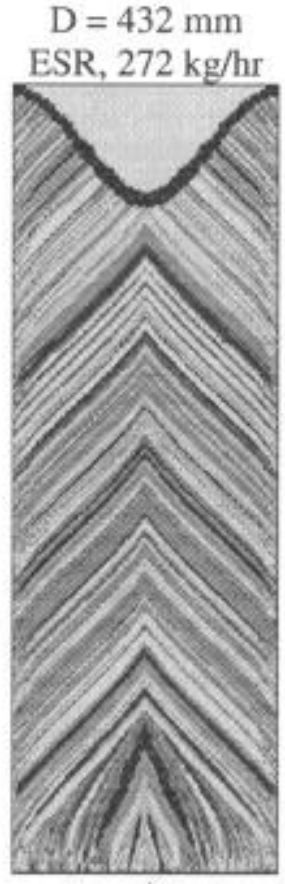

c)

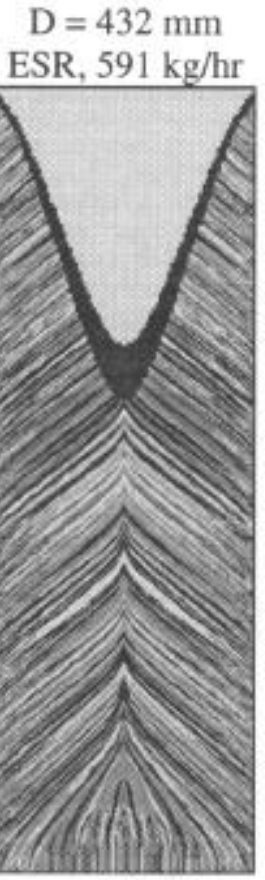

d)

Figure 2 - Comparison between simulated structures of VAR and ESR alloy 718 remelt ingots for various melting rates: a) $\mathrm{H}=2 \mathrm{D}, \mathrm{b}) \mathrm{H}=2 \mathrm{D}$, c) $\mathrm{H}=3 \mathrm{D}$, d) $\mathrm{H}=3 \mathrm{D}$.

A total of 255 colors were used in the solid region to describe the grain boundary of dendritic equiaxed and columnar structures. The colors also show the crystallographic orientation of columnar grains which have nucleated at the ingot/mold interface. The nucleation and growth competition of columnar grains can clearly be seen in Fig. 2. These grains randomly nucleate at the ingot/mold interface and grow toward the ingot center. Note, that the grains also grow in a direction opposite to the withdrawal direction (upward solidification), closely following the direction of mushy region gradients. Steady state in both VAR and ESR processes is reached when the height of the ingot equals its diameter $(\mathrm{H}=\mathrm{D})$. The simulated ESR ingots, presented in Figs. 2c and 2d, have V-shaped pool profiles with nonuniform columnar grain size distribution from the ingot center to the outside edge. The simulated VAR ingots (Figs $2 \mathrm{a}$ and $2 \mathrm{~b}$ ) have $\mathrm{U}$-shaped pool profiles with relatively uniform columnar grain size distribution. The grain growth direction in the ESR ingots is between $0^{\circ}$ (at the ingot surface) and $45^{\circ}$ (at the ingot center) with respect to the ingot vertical axis, while in the VAR ingots the grain growth direction is between $90^{\circ}$ (at the ingot surface) and $0^{\circ}$ (at the ingot center). The smaller the growth angle at the ingot center, the lower the tendency would be to form the 
CET and the major segregation zone at the ingot center. The grain growth direction is mostly controlled by the power input and power distribution over the top surface of the ingot. Accordingly, a VAR ingot will have a very different grain structure from that of an ESR ingot.

\section{Modeling of Secondary Phases during Solidification of Alloy 718 Remelt Ingots}

A typical SEM micrograph shown in Fig. $3[3,11]$ illustrates the morphology of Laves phases and $\mathrm{NbC}$ particles (blocky type) segregated in the interdendritic regions (between secondary dendrite arms) of alloy 718 at a cooling rate of $2 \mathrm{~K} / \mathrm{s}$. It can be seen from Fig. 3 that approximately $70 \%$ of $\mathrm{NbC}$ particles are located at the grain boundary, while the remaining $30 \%$ are found in the intradendritic regions. In the current model, Eqs. (4)-(7) were used to calculate the redistribution of $\mathrm{NbC}$ particles during solidification. When the $\mathrm{S} / \mathrm{L}$ interface velocity is larger than the minimum critical velocity of PET, NbC particles will be engulfed. Otherwise, they will be either pushed or engulfed (or entrapped) based on stochastic calculations. Note that, the stochastic model accounts for the effect of the S/L dendritic interface roughness and other mechanisms, such as sliding/rolling [14] and solute redistribution, on PET. Figure 4 shows the stochastic calculations of the redistribution of $\mathrm{NbC}$ particles between the solid and liquid phases for the case presented in Fig. 3. The final average liquid (particles located in the interdendritic regions) and solid (particles located in the intradendritic regions) $\mathrm{NbC}$ populations in Fig. 4 are about $1.5 \times 10^{13}$ particles $/ \mathrm{m}^{3}$ and $7.5 \times 10^{12}$ particles $/ \mathrm{m}^{3}$, respectively. The total number of $\mathrm{NbC}$ particles $/ \mathrm{m}^{3}$, including both intradendritic and interdendritic regions, is approximately $2.25 \times 10^{13}$. This result matches closely with the experiment shown in Fig. 3.

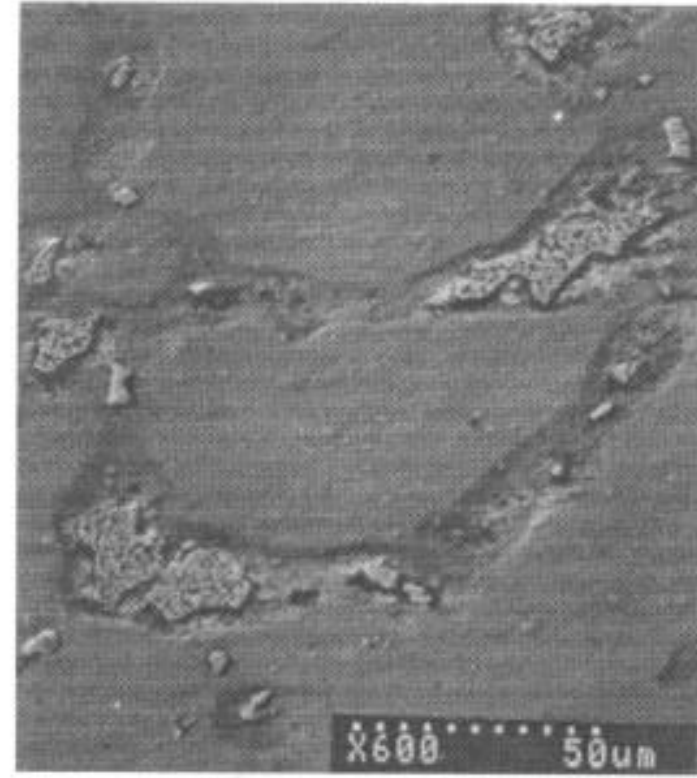

Figure 3 - SEM micrograph showing Laves phases and $\mathrm{NbC}$ particles segregated in the interdendritic regions for cast alloy 718 (cooling rate was approximately $2 \mathrm{~K} / \mathrm{s}$ ), $600 \times[3,11]$.

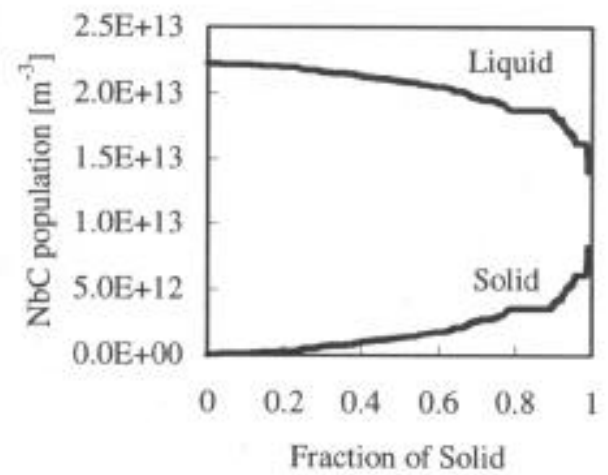

Figure 4 - Stochastic redistribution of $\mathrm{NbC}$ particles during solidification of cast alloy 718 for a cooling rate of about $2 \mathrm{~K} / \mathrm{s}$. The initial $\mathrm{C}$ and $\mathrm{Nb}$ concentrations were $0.06 \mathrm{wt} . \%$ and $5.25 \mathrm{wt}$. \%, respectively. The upper and lower lines show the average $\mathrm{NbC}$ populations $\left[\mathrm{m}^{-3}\right]$ in the liquid and solid, respectively. The cooling rate was numerically calculated immediately above the equilibrium liquidus temperature. The average liquid and solid $\mathrm{NbC}$ populations were calculated relative to the final instability (secondary dendrite arm radius) volume. 
Figure 5 depicts the average $\mathrm{NbC}$ population $\left[\mathrm{m}^{-3}\right]$ in the last liquid region as a function of the cooling rate with and without modeling of PET. Cooling rates were calculated at the beginning of solidification, and their range covers those encountered in VAR and ESR ingots. The average liquid $\mathrm{NbC}$ population increases monotonously when PET is neglected. However, when PET is considered, a decrease in the average liquid NbC population occurs for cooling rates above $5 \mathrm{~K} / \mathrm{s}$. This complex behavior is associated with the ratio between the critical velocity of PET and the S/L interface velocity that is, in fact, the PET probability. The higher the cooling rate, the bigger is the PET probability in Eq. (7) (i.e., entrapment/engulfment of particles is favored). This trend is also related to the variation of the final instability radius (secondary dendrite arm radius) with the cooling rate as presented in Fig. 6 and to the linear dependency of the final $\mathrm{NbC}$ carbide radius with the cooling rate as shown above.

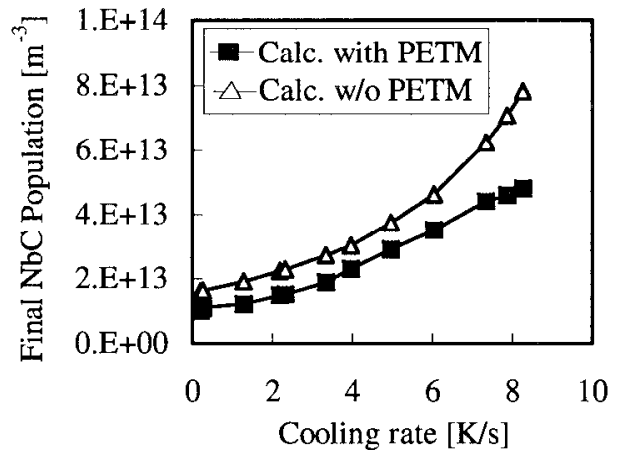

Figure 5 - Calculated variation of the final average liquid $\mathrm{NbC}$ population $\left[\mathrm{m}^{-3}\right]$ as a function of the cooling rate for cast alloy

718. NbC population represents the number of carbides precipitated per unit of volume.

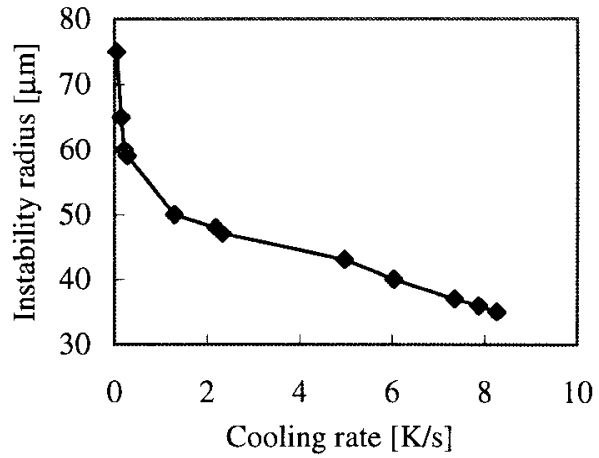

Figure 6 - Calculated variation of the final instability radius (secondary dendrite arm radius) as a function of the cooling rate for cast alloy 718 .

The redistribution of both solid and liquid $\mathrm{NbC}$ populations during solidification is crucial since it will affect the size and amount of $\mathrm{NbC}$ particles and Laves phases. The influence of the cooling rate on the amount of eutectic $(\gamma+$ Laves $)$ and $\mathrm{NbC}$ precipitated in alloy 718 ingots is presented in Figs. 7 and 8, respectively. As the cooling rate increases, the amount of precipitated $\mathrm{NbC}$ decreases, and falls short of the maximum (equilibrium) amount which is about $0.6 \mathrm{wt}$. \%. On the contrary, as the cooling rate increases, the amount of Laves phases increases up to a maximum amount of $4.3 \mathrm{wt} . \%$ and then slightly decreases. Note, that a calculation with Scheil's model predicted $8.34 \mathrm{wt}$. \% Laves phase, irrespective of the cooling rate. Since the amount of Laves phase is proportional with the intensity of $\mathrm{Nb}$ segregation, the maximum in Fig. 8 is connected to the evolution of the diffusional time in both solid and liquid phases, and related to the redistribution of $\mathrm{NbC}$ particles between the solid and liquid phases. The existence of a critical cooling rate at which maximum segregation, and thus maximum amount of Laves phases can form, has significant practical importance. By controlling process parameters, it might be possible to avoid significant amounts of Laves phases in the microstructure. The effects of redistribution of $\mathrm{NbC}$ particles during solidification (Fig. 5) on the amounts of $\mathrm{NbC}$ and Laves phases can be seen from Figs. 7 and 8 , particularly for cooling rates below $5 \mathrm{~K} / \mathrm{s}$. The calculated amounts of Laves phase with and without PET modeling coincide for cooling rates higher than $5 \mathrm{~K} / \mathrm{s}$. In this case, the effect of the cooling rate on the formation of Laves phases prevails over that due to redistribution of $\mathrm{NbC}$ particles. 


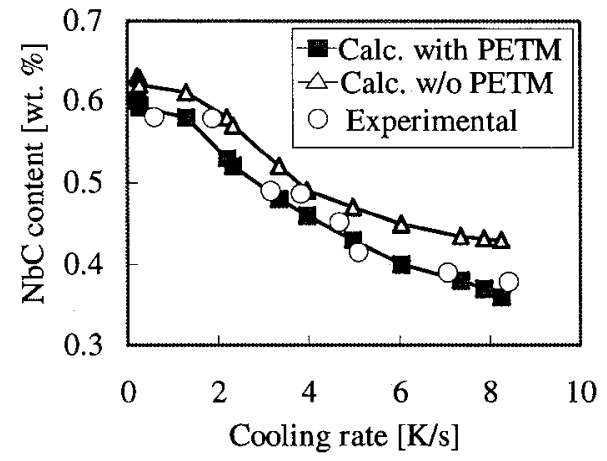

Figure 7 - Experimental $[3,8,11]$ and current model calculated amounts of $\mathrm{NbC}$ phase as a function of the cooling rate, where PETM is the PET model.

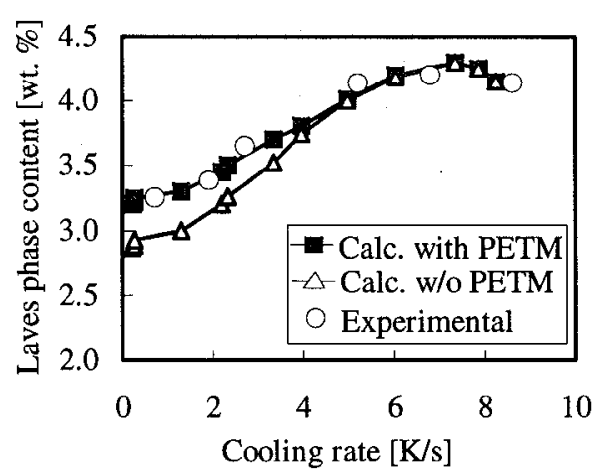

Figure 8 - Experimental $[3,8,11]$ and current model calculated amounts of Laves phases as a function of the cooling rate, where PETM is the PET model.

Table II shows a thorough comparison between calculated and experimental results for alloy 718 VAR and ESR ingots. The results are presented in terms of pool depth, secondary dendrite arm spacing (SDAS), and amounts of secondary phases for two melting rates. The pool depth and the amount of Laves phases increase with power input and melting rate, while SDAS and the amount of $\mathrm{NbC}$ decrease. There are insignificant differences between ESR and VAR results in terms of size of SDAS as well as size and contents of secondary phases. The calculated pool depth and SDAS agree closely with the experimental measurements. Under the present solidification conditions, when the $\mathrm{C}$ and $\mathrm{Nb}$ compositions of the melt are $0.06 \mathrm{wt}$. $\%$ and $5.25 \mathrm{wt} . \%$, respectively, there is a small effect of the $\mathrm{NbC}$ content on the segregation and, therefore, on the amount of Laves phases.

Table III presents calculated results of the effect of the melting rate and the initial $\mathrm{C}$ and $\mathrm{Nb}$ concentrations on the amounts of $\mathrm{NbC}$ and Laves phases precipitated at the interdendritic and intradendritic regions for the two VAR cases shown in Table II. These results are shown only for the steady-state condition, when $\mathrm{H}=3 \mathrm{R}$. Note, that in the present calculations, convection and macrosegregation phenomena are neglected. They may alter the present results, particularly for low cooling rates encountered in the center of the ingot. As shown in Table III, particularly for large cooling rates encountered at the ingot edge, the amount of the Laves phases formed is strongly dependent on the local cooling rates and on the initial $\mathrm{Nb}$ content and less on the initial $\mathrm{C}$ content. A similar trend is observed for $\mathrm{NbC}$, i.e., the amount of precipitated $\mathrm{NbC}$ is controlled by the initial $\mathrm{C}$ content and by local cooling rates, and is slightly affected by the amount of the Laves phases.

Our calculations in Table III reveal that combinations between $\mathrm{C}$ and $\mathrm{Nb}$ as a function of the cooling rate can be used to control the amount of both $\mathrm{NbC}$ and Laves phases. In VAR and ESR ingots, an initial $\mathrm{Nb}$ content of $4.75 \mathrm{wt} . \%$ and a minimum initial C content of 0.12 wt. \% are required to obtain a Laves-free microstructure with maximum $1.25 \mathrm{wt}$. \% $\mathrm{NbC}$ phase. Also, cooling rates below $5 \mathrm{~K} / \mathrm{s}$ will favor the formation of low amounts of $\mathrm{NbC}$ and Laves phases, and NbC particles will be mostly segregated at the grain boundary. Results from this type of calculation can provide useful information for understanding the formation tendency of freckle-type defects in VAR and ESR ingots. 
Table II Comparison between calculated and experimental results for alloy 718 remelt ingots

\begin{tabular}{|c|c|c|c|c|c|c|c|c|c|}
\hline \multicolumn{2}{|l|}{ Ingot Type } & \multicolumn{2}{|c|}{ VAR } & \multicolumn{2}{|c|}{ VAR } & \multicolumn{2}{|c|}{ ESR } & \multicolumn{2}{|c|}{ ESR } \\
\hline \multicolumn{2}{|l|}{ Power Input [KW] } & \multicolumn{2}{|c|}{125} & \multicolumn{2}{|c|}{200} & \multicolumn{2}{|c|}{240} & \multicolumn{2}{|c|}{530} \\
\hline \multicolumn{2}{|c|}{ Melting Rate $[\mathrm{kg} / \mathrm{hr}]$} & \multicolumn{2}{|c|}{172} & \multicolumn{2}{|c|}{327} & \multicolumn{2}{|c|}{272} & \multicolumn{2}{|c|}{591} \\
\hline \multicolumn{2}{|c|}{ Ingot Diameter [mm] } & \multicolumn{2}{|c|}{508} & \multicolumn{2}{|c|}{508} & \multicolumn{2}{|c|}{432} & \multicolumn{2}{|c|}{432} \\
\hline Results $^{a}$ & & Calc. & Exp. & Calc. & Exp. & Calc. & Exp. & Calc. & Exp. \\
\hline Pool depth ${ }^{b}[\mathrm{~mm}]:$ & $\begin{array}{l}\mathrm{H}=0.5 \mathrm{R} \\
\mathrm{H}=\mathrm{R} \\
\mathrm{H}=3 \mathrm{R}\end{array}$ & $\begin{array}{c}41 \\
102 \\
147 \\
\end{array}$ & $\begin{array}{c}- \\
84 \\
152 \\
\end{array}$ & $\begin{array}{c}81 \\
183 \\
365 \\
\end{array}$ & $\begin{array}{c}- \\
- \\
381\end{array}$ & $\begin{array}{c}44 \\
98 \\
158 \\
\end{array}$ & $\begin{array}{c}- \\
- \\
152\end{array}$ & $\begin{array}{c}67 \\
175 \\
376 \\
\end{array}$ & $\begin{array}{c}- \\
- \\
363\end{array}$ \\
\hline SDAS $[\mu \mathrm{m}]$, center: & $\begin{array}{l}\mathrm{H}=0.5 \mathrm{R} \\
\mathrm{H}=\mathrm{R} \\
\mathrm{H}=3 \mathrm{R}\end{array}$ & $\begin{array}{l}136 \\
137 \\
138\end{array}$ & $\begin{array}{c}- \\
- \\
132\end{array}$ & $\begin{array}{l}117 \\
118 \\
120\end{array}$ & $\begin{array}{c}- \\
i \\
114\end{array}$ & $\begin{array}{l}112 \\
115 \\
118\end{array}$ & $\begin{array}{c}117 \\
- \\
108\end{array}$ & $\begin{array}{l}85 \\
87 \\
89\end{array}$ & $\begin{array}{c}- \\
- \\
82\end{array}$ \\
\hline SDAS $[\mu \mathrm{m}]$, mid-radius: & $\begin{array}{l}\mathrm{H}=0.5 \mathrm{R} \\
\mathrm{H}=\mathrm{R} \\
\mathrm{H}=3 \mathrm{R}\end{array}$ & $\begin{array}{l}125 \\
126 \\
128 \\
\end{array}$ & $\begin{array}{c}- \\
- \\
117\end{array}$ & $\begin{array}{l}117 \\
118 \\
120\end{array}$ & $\overline{-}$ & $\begin{array}{l}112 \\
114 \\
118\end{array}$ & $\begin{array}{c}107 \\
- \\
111\end{array}$ & $\begin{array}{l}72 \\
74 \\
78\end{array}$ & $\begin{array}{l}- \\
- \\
-\end{array}$ \\
\hline SDAS $[\mu \mathrm{m}]$, edge $^{c}$ : & $\begin{array}{l}H=0.5 R \\
H=R \\
H=3 R\end{array}$ & $\begin{array}{c}96 \\
98 \\
101\end{array}$ & $\begin{array}{c}- \\
- \\
103\end{array}$ & $\begin{array}{l}96 \\
97 \\
99\end{array}$ & $\overline{-}$ & $\begin{array}{l}76 \\
79 \\
81\end{array}$ & $\begin{array}{c}76 \\
- \\
71\end{array}$ & $\begin{array}{l}66 \\
70 \\
74\end{array}$ & $\begin{array}{l}- \\
- \\
65\end{array}$ \\
\hline Laves [wt. \%], center: & $\begin{array}{l}\mathrm{H}=0.5 \mathrm{R} \\
\mathrm{H}=\mathrm{R} \\
\mathrm{H}=3 \mathrm{R}\end{array}$ & $\begin{array}{l}3.17 \\
3.16 \\
3.15 \\
\end{array}$ & - & $\begin{array}{l}3.24 \\
3.22 \\
3.21 \\
\end{array}$ & - & $\begin{array}{l}3.19 \\
3.18 \\
3.17 \\
\end{array}$ & - & $\begin{array}{l}3.25 \\
3.24 \\
3.22 \\
\end{array}$ & - \\
\hline Laves [wt. \%], mid-radius: & $\begin{array}{l}\mathrm{H}=0.5 \mathrm{R} \\
\mathrm{H}=\mathrm{R} \\
\mathrm{H}=3 \mathrm{R}\end{array}$ & $\begin{array}{l}3.19 \\
3.18 \\
3.16\end{array}$ & $\begin{array}{l}- \\
- \\
-\end{array}$ & $\begin{array}{l}3.25 \\
3.24 \\
3.22 \\
\end{array}$ & - & $\begin{array}{l}3.20 \\
3.20 \\
3.18\end{array}$ & $\begin{array}{l}- \\
- \\
-\end{array}$ & $\begin{array}{l}3.26 \\
3.25 \\
3.23\end{array}$ & - \\
\hline Laves [wt. \%], edge ${ }^{c}$ : & $\begin{array}{l}H=0.5 \mathrm{R} \\
\mathrm{H}=\mathrm{R} \\
\mathrm{H}=3 \mathrm{R}\end{array}$ & $\begin{array}{l}3.31 \\
3.26 \\
3.23 \\
\end{array}$ & $\begin{array}{l}- \\
- \\
-\end{array}$ & $\begin{array}{l}3.46 \\
3.38 \\
3.34 \\
\end{array}$ & - & $\begin{array}{l}3.45 \\
3.35 \\
3.28 \\
\end{array}$ & $\begin{array}{l}- \\
- \\
-\end{array}$ & $\begin{array}{c}3.7 \\
3.5 \\
3.46 \\
\end{array}$ & $\begin{array}{l}- \\
- \\
\end{array}$ \\
\hline $\mathrm{NbC}$ [wt. \%], center: & $\begin{array}{l}\mathrm{H}=0.5 \mathrm{R} \\
\mathrm{H}=\mathrm{R} \\
\mathrm{H}=3 \mathrm{R}\end{array}$ & $\begin{array}{l}0.60 \\
0.61 \\
0.62 \\
\end{array}$ & - & $\begin{array}{l}0.59 \\
0.60 \\
0.61 \\
\end{array}$ & - & $\begin{array}{l}0.60 \\
0.60 \\
0.61 \\
\end{array}$ & $\begin{array}{l}- \\
- \\
\end{array}$ & $\begin{array}{l}0.59 \\
0.59 \\
0.60 \\
\end{array}$ & - \\
\hline NbC [wt. \%], mid-radius: & $\begin{array}{l}H=0.5 R \\
H=R \\
H=3 R\end{array}$ & $\begin{array}{l}0.59 \\
0.59 \\
0.60 \\
\end{array}$ & $\begin{array}{l}- \\
- \\
-\end{array}$ & $\begin{array}{l}0.58 \\
0.59 \\
0.60 \\
\end{array}$ & - & $\begin{array}{l}0.58 \\
0.59 \\
0.60 \\
\end{array}$ & $\begin{array}{l}- \\
- \\
-\end{array}$ & $\begin{array}{l}0.58 \\
0.58 \\
0.59 \\
\end{array}$ & $\begin{array}{l}- \\
- \\
-\end{array}$ \\
\hline NbC [wt. \%], edge ${ }^{c}:$ & $\begin{array}{l}\mathrm{H}=0.5 \mathrm{R} \\
\mathrm{H}=\mathrm{R} \\
\mathrm{H}=3 \mathrm{R}\end{array}$ & $\begin{array}{l}0.55 \\
0.57 \\
0.58\end{array}$ & $\begin{array}{l}- \\
- \\
-\end{array}$ & $\begin{array}{l}0.51 \\
0.53 \\
0.54\end{array}$ & - & $\begin{array}{l}0.52 \\
0.56 \\
0.57\end{array}$ & $\begin{array}{l}- \\
- \\
-\end{array}$ & $\begin{array}{l}0.48 \\
0.52 \\
0.53\end{array}$ & - \\
\hline
\end{tabular}

a The experimental measurements of pool depth and SDAS were taken from Refs. [7, 16-18].

${ }^{b}$ Steady-state region is reached for $\mathrm{H}=3 \mathrm{R}$, where $\mathrm{R}$ is the ingot radius.

${ }^{c}$ Results are shown at $12.7 \mathrm{~mm}$ from the ingot edge for VAR and along the ingot edge for ESR.

Table III Calculated results showing the effect of the melting rate and the initial $\mathrm{C}$ and $\mathrm{Nb}$ concentrations on the precipitated amounts of $\mathrm{NbC}$ and Laves phases [wt. \%] for the two

VAR ingots presented in Table II. The results are shown at steady-state ( $\mathrm{H}=3 \mathrm{R})$.

\begin{tabular}{|c|c|c|c|c|c|c|c|c|c|c|c|c|c|}
\hline \multirow{2}{*}{\multicolumn{2}{|c|}{$\begin{array}{c}\text { Ingot Location } \\
\text { Controlling Factors }\end{array}$}} & \multicolumn{4}{|c|}{ Center } & \multicolumn{4}{|c|}{ Mid-radius } & \multicolumn{4}{|c|}{ Edge } \\
\hline & & \multicolumn{12}{|c|}{$\mathrm{C}$ [wt. \%] } \\
\hline \multirow{2}{*}{$\begin{array}{c}\text { Melting } \\
\text { Rate }[\mathrm{kg} / \mathrm{hr}]\end{array}$} & \multirow{2}{*}{$\begin{array}{c}\mathrm{Nb} \\
\text { [wt. \%] }\end{array}$} & \multicolumn{2}{|c|}{0.02} & \multicolumn{2}{|c|}{0.12} & \multicolumn{2}{|c|}{0.02} & \multicolumn{2}{|c|}{0.12} & \multicolumn{2}{|c|}{0.02} & \multicolumn{2}{|c|}{0.12} \\
\hline & & $\mathrm{NbC}$ & Lav. & $\mathrm{NbC}$ & Lav. & $\mathrm{NbC}$ & Lav. & $\mathrm{NbC}$ & Lav. & $\mathrm{NbC}$ & Lav. & $\mathrm{NbC}$ & Lav. \\
\hline \multirow[t]{2}{*}{172} & 4.75 & 0.21 & 2.51 & 1.25 & 0.00 & 0.20 & 2.53 & 1.21 & 0.00 & 0.19 & 2.71 & 1.15 & 0.00 \\
\hline & 5.75 & 0.20 & 3.71 & 1.20 & 0.00 & 0.19 & 3.75 & 1.16 & 0.05 & 0.18 & 4.04 & 1.12 & 0.27 \\
\hline \multirow[t]{2}{*}{327} & 4.75 & 0.19 & 2.62 & 1.23 & 0.00 & 0.18 & 2.66 & 1.18 & 0.00 & 0.17 & 2.82 & 1.04 & 0.11 \\
\hline & 5.75 & 0.18 & 3.82 & 1.18 & 0.11 & 0.17 & 3.89 & 1.15 & 0.21 & 0.16 & 4.18 & 0.99 & 0.51 \\
\hline
\end{tabular}




\section{Concluding Remarks and Future Work}

A state-of-the-art simulation tool was developed to describe the evolution of grain structure and secondary phases ( $\mathrm{NbC}$ and eutectic-I aves phases) during solidification of VAR and ESR remelt ingots. Simulated pool profile, grain structure, grain-growth pattern, secondary dendrite arm spacing, and the distribution (PET) and amount of secondary phases agreed closely with experimental data. This simulation tool can provide useful information for optimizing VAR and ESR ingot micro/macrostructure. Future development efforts are to include the effects of fluid flow, macrosegregation, and electromagnetic field on the stochastic calculations.

\section{Acknowledgments}

This work was conducted by the National Center for Excellence in Metalworking Technology, operated by Concurrent Technologies Corporation under cóntract No. N0014092-C-BC49 to the U.S. Navy as part of the U.S. Navy Manufacturing Technology Program. Howard A. Kuhn, Yuan Pang, Michael L. Tims, and Leila A. Bearjar from Concurrent Technologies Corporation are acknowledged for their comments and suggestions in writing this paper.

\section{References}

1. COMPACT ${ }^{\mathrm{TM}}$, Innovative Research Inc., Minneapolis, MN, 1996.

2. L. Nastac, S. Sundarraj, K. O. Yu, and Y. Pang: Proceedings of the 1997 International Symposium on Liquid Metals Processing and Casting, Vacuum Metallurgy Division, American Vacuum Society, edited by A. Mitchell and P. Aubertin, 1997, pp. 145-165.

3. L. Nastac: PhD Dissertation, The University of Alabama, Tuscaloosa, 1995.

4. G. K. Upadhya, K. O. Yu, M. A. Layton, and A. J. Paul: Modeling of Casting, Welding and Advanced Solidification Processes, edited by M. Cross and J. Campbell, TMS, 1995, pp. 517-24.

5. L. Nastac and D. M. Stefanescu: submitted to Modelling and Simulation in Materials Science and Engineering, Institute of Physics Publishing, November 1996.

6. H. Pang and D. M. Stefanescu: Solidification Science and Processing, Edited by I. Ohnaka and D. M. Stefanescu, TMS, 1996.

7. K. O. Yu and H. D. Flanders: Proceedings of the Vacuum Metallurgy Conference on Specialty Metals, Melting and Processing, 1984, pp. 107-118.

8. L. Nastac and D. M. Stefanescu, submitted to Met. Trans A, December 1996.

9. B. Radhakrishnan and R. G. Thompson, MeT. Trans A, Vol. 22 A, 1991, pp. 887-902.

10. C. Chen, R. G. Thompson, and D. W. Davis, Superalloys 718,625 and Various Derivatives, edited by E. A. Loria, The Minerals, Metals \& Materials Society, 1991, pp. 81-96.

11. L. Nastac and D. M. Stefanescu: Met. Trans., Vol. 27 A, 1996, pp. 4061-74 and pp. 407583.

12. L. Nastac and D. M. Stefanescu: Met. Trans., Vol. 24 A, 1993, pp. 2107-18.

13. D. Shangguan, S. Ahuja, and D. M. Stefanescu: Met. Trans., Vol. 23 A, 1992, pp. 669-80.

14. Q. Han and J. D. Hunt: Trans. Iron Steel Inst. Jpn., Vol. 35, 1995, pp. 683-99.

15. M. Rappaz and V. Voller: Met. Trans., Vol. 21 A, 1990, pp. 749-53.

16. K. O. Yu: Proceedings of the Vacuum Metallurgy Conference on Specialty Metals, Melting and Processing, 1984, pp. 83-92.

17. K. O. Yu: Internal Report, Special Metals Corporation, 1982.

18. K. O. Yu, J. A. Domingue, and H. D. Flanders: Proceedings of the $8^{\text {th }}$ International Conference on Vacuum Metallurgy, 1985. 